ISSN 2073-4409

www.mdpi.com/journal/cells

\title{
Correction
}

\section{Correction: Sadofsky, L.R., et al. Unique Responses are Observed in Transient Receptor Potential Ankyrin 1 and Vanilloid 1 (TRPA1 and TRPV1) Co-Expressing Cells. Cells 2014, 3, 616-626}

Laura R. Sadofsky ${ }^{1}$, Koti T. Sreekrishna ${ }^{2, *}$, Yakang Lin ${ }^{2}$, Renee Schinaman ${ }^{2}$, Kate Gorka ${ }^{2}$, Yogita Mantri ${ }^{2}$, John Christian Haught ${ }^{2}$, Thomas G. Huggins ${ }^{2}$, Robert J. Isfort ${ }^{2}$, Charles C. Bascom ${ }^{2}$ and Alyn H. Morice ${ }^{1}$

1 Cardiovascular and Respiratory Studies, The University of Hull, HU6 7RX, UK; E-Mails: Sadofsky@hull.ac.uk (L.R.S.); A.H.Morice@hull.ac.uk (A.H.M.)

2 The Procter \& Gamble Company, Mason, OH 45040, USA; E-Mails: lin.y.2@Pg.com (Y.L.); schinaman.cr@pg.com (R.S.); gorka.k@pg.com (K.G.); mantri.y@pg.com (Y.M.); haught.c@pg.com (J.C.H.); huggins.tg@pg.com (T.G.H.); Isfort.rj@pg.com (R.J.I.); bascom.cc@pg.com (C.C.B.)

* Author to whom correspondence should be addressed; E-Mail: Sreekrishna.k@pg.com; Tel.: +1-513-622-1431; Fax: +1-513-622-0887.

Received: 3 September 2014 / Accepted: 4 September 2014 / Published: 27 October 2014

The authors wish to make the following corrections to this paper [1]:

In Table 2 on page 623, the Quercinitol activation value for TRPA1V1 should be 2.3 instead of 57.6. Quercinitol does not activate TRPA1V1. We thank Michael J.M. Fisher (University of Erlangen, Germany) for his feedback which helped us to review our result.

The authors would like to apologize for any inconvenience caused to the readers by these changes. 


\section{Reference}

1. Sadofsky, L.R.; Sreekrishna, K.T.; Lin, Y.; Schinaman, R.; Gorka, K.; Mantri, Y.; Haught, J.C.; Huggins, T.G.; Isfort, R.J.; Bascom, C.C.; et al. Unique responses are observed in transient receptor potential Ankyrin 1 and Vanilloid 1 (TRPA1 and TRPV1) co-expressing cells. Cells 2014, 3, 616-626.

(C) 2014 by the authors; licensee MDPI, Basel, Switzerland. This article is an open access article distributed under the terms and conditions of the Creative Commons Attribution license (http://creativecommons.org/licenses/by/4.0/). 